\title{
Affect and Memory in Young Children'
}

\author{
S. Wayne Duncan, Christine M. Todd, and Marion Perlmutter ${ }^{2}$ \\ University of Minnesota \\ John C. Masters ${ }^{2}$ \\ Vanderbilt University
}

The state-dependent theory of the relationship between affective states and memory holds that recall will be best when the affective state at recall matches that during learning. Sequential happy, neutral, and sad affective states that were either consistent (e.g., Happy-Happy) or inconsistent (e.g., Sad-Neutral) were experimentally induced in preschool children prior to encoding and then again prior to retrieval (free and cued recall, recognition memory). Facial ratings indicated that the inductions were effective in inducing affect. Nevertheless, emotional states did not influence children's ability to recall items under free or cued conditions, and recognition memory was essentially perfect for all subjects. Thus, there was no evidence for state-dependent learning or for a "positive loop" between subjects" positive affect at retrieval and memory for positively rated information. Results are discussed in terms of the generally inconsistent findings in the literature on the role of affect in children's memory and factors that may limit affective state-dependent learning in children.

\footnotetext{
${ }^{1}$ This research was supported by Research Grant No. 11776 from the National Institute of Child Health and Human Development to Marion Perlmutter, by Grant BNS 78-01108 from the National Science Foundation to John C. Masters, and by Program Project Grant No. 0527 to the Institute of Child Development. Wayne Duncan is now at the University of Denver, and Christine Todd is now at the University of Illinois, Urbana. Marion Perlmutter is now at the University of Michigan. We would like to thank Keith Elliott and LuAnne Tczap for their work as experimenters; Jule Kogan, Carol Revermann, and Sonya Hernandez for their help in coding data; and Jayne Grady-Reitan for her administrative assistance throughout the study. ${ }^{2}$ Address all correspondence to Marion Perlmutter, Department of Psychology, 3433 Mason Hall, University of Michigan, Ann Arbor, Michigan 48109, or to John C. Masters, Vanderbilt Institute for Public Policy Studjes, 1208 18th Avenue South, Nashville, Tennessee 37212.
} 
During the last decade considerable research attention has been focused on children's emotional development. Of particular note has been the study of children's mood states and their effects on various patterns of social behavior. Experimental procedures to induce affective states have been shown to be valid, and children's moods have been demonstrated to influence their social behavior with other children (Barden, Garber, Duncan, \& Masters, 1981; Harris \& Siebel, 1975; Moore, Underwood, \& Rosenhan, 1973; Rosenhan, Underwood, \& Moore, 1974; Underwood, Moore, \& Rosenhan, 1973). The publication of both convergent and discriminant validity data on the induction procedure (Masters, Barden, \& Ford, 1979; Teasdale \& Taylor, 1981) has encouraged the utilization of experimentally induced affective states to explore the influence of emotion on learning (Masters et al., 1979) and other cognitive processes under carefully controlled experimental conditions.

The present paper reports a study of the influence of young children's affective states on their memory. In addition to being of interest in its own right, the role of affect in memory may constitute one of the cognitive factors mediating the effects of mood states on behavior. For example, the manner in which children recall information about a particular past event or experience may mediate the child's reaction to other similar events in the present (Reichenbach, 1984). As such, the role of affect in memory may be a critical one in understanding the link between cognition and behavior.

During the last decade the study of children's memory development has flourished (see Ornstein, 1978). This extensive empirical effort, however, has largely centered around delineating the varied strategies children employ to remember information. For example, these studies have repeatedly demonstrated that children become increasingly competent users of strategies with age. However, even young children demonstrate fairly good performance when given developmentally appropriate tasks (Todd \& Perlmutter, 1980). Unfortunately, this emphasis on strategies has led to a neglect of other areas of potential importance for understanding memory development (Brown, Bransford, Ferrara, \& Campione, 1983).

One such area is that of the context of learning. This has typically been conceptualized as the physical environment in which the learning occurs or as the learner's internal knowledge base. However, little attention has been paid to the potentially important role affect may play as a context for learning and memory, especially in children. Two lines of research suggest possibly important reasons for attention to this area: work on concept development in children, and research on state-dependent learning in adults.

Considerable work has documented the increasing sophistication of children in their usage of categories as they grow older (e.g., Markman, 
1981). Such work has pointed out the importance of category labels and semantic cues for school-age children's memory performance. Preschool children will also use semantic cues if prompted but do not spontaneously use them (Perlmutter \& Myers, 1979). Since traditional category cues tend not to be utilized automatically by very young children, other aspects of the internal context for learning and memory may become important, and it can be proposed that affective context might serve as an effective retrieval cue. In the present study, affective states were induced in children and their free recall was assessed for information learned in an incidental memory task. It was reasoned that such a task would maximize the likelihood that children would use the affective context as a retrieval cue.

The second major area of relevant work is that of state-dependent learning. Though only a few studies have been conducted with children (e.g., Bartlett \& Santrock, 1979; Nasby \& Yando, 1982), this phenomenon has been consistently demonstrated in adults and animals with the use of drug-induced states (Weingartner, 1984). Of particular interest has been the finding that mood-altering substances (e.g., marijuana, alcohol) are effective in altering memory performance in specific ways. When information is learned while the subject is in a certain substance-induced state, that information is recalled best when the subject is again in that state, but the effect is reduced or eliminated completely when category cues are used by adult subjects (Colpaert \& Rosecrans, 1978). This suggests that an affect state would provide a particularly important context for learning and memory in young children since they are not likely to make spontaneous use of category cues.

The present study was designed to examine the role of affect in young children's recall and recognition of visually presented material. Nonpurposive or incidental memory was of interest in this study since this type of memory is most common with kindergarten-age children (Istomina, 1948/1975; Todd \& Perlmutter, 1980). Although most studies of children's incidental memory assess recall immediately after presentation of the items, in the present experiment a delay of 15 minutes was employed to reflect more closely naturally occurring conditions. During this interval there was a play period that effectively separated the encoding and retrieval processes, thus requiring the child to retrieve information from long-term memory.

The primary hypothesis was that affect would influence children's free-recall performance but not cued recall or recognition memory. It was hypothesized that in a free-recall task, which requires internal memory search in the absence of external memory cues, affect may serve as an effective retrieval mechanism in locating information that is affectively linked. By contrast, the presence of the original memory stimulus in recognition tasks or the provided categorical label in cued recall tasks may obviate the 
need to employ affective cues to aid retrieval. Thus, only in free recall should any internal affective cues be expected to function effectively. The second hypothesis was that retention would be enhanced by a match between affective state at encoding and retrieval (e.g., positive/positive, negative/negative), that is, that the influence of emotion on recall would follow a state-dependent model.

\section{METHOD}

\section{Subjects and Researchers}

Seventy-two 4- and 5-year-old children participated in the study $(M=$ 5.0 , range $=4$ years 7 months to 5 years 7 months). The children were from predominantly white middle-class families. The experimenters were two undergraduate psychology students, one of each sex.

\section{Procedural Overview}

The female experimenter was assigned the role of affect inducer and the male experimenter directed the child through the memory tasks. Each child participated in two affect inductions, one before the encoding of the stimuli and one prior to retrieval. A $3 \times 3$ experimental design was used in which one of three affective states (happy, neutral, sad) induced at encoding was crossed with one of three affective states induced at retrieval. Thus, there were nine possible combinations of encoding and retrieval affect; three were consistent (e.g., Happy-Happy) and six were not (e.g., Happy-Sad). The children's memory for pictorial stimuli was examined through free recall, cued recall, and recognition memory tasks. Children's self-reports of affective state as well as videotape recordings of facial expressions were obtained prior to and following each of the two affect inductions in order to confirm the effectiveness of the induction procedure.

\section{Affect Induction}

The affect induction procedure for the present experiment was based upon a standard cognitive induction procedure that has been used successfully in a number of studies (e.g., Barden et al., 1981; Barden, Garber, Leiman, Ford, \& Masters, 1985; Moore et al., 1973; Rosenhan et al., 1974; Underwood et al., 1973) and has been validated using independent measures of affect (Masters et al., 1979). In this procedure, children generate 
a thought of a particular affective valence and then dwell upon it for a brief period of time (typically, 30 seconds). For the present study, the induction procedure was further strengthened by the addition of a vicarious component (cf. Barden et al., 1985) that involved showing the child pictures of other children and families experiencing the state being induced.

The elements of the overall affect induction procedure were as follows: In succession, the child was shown each of the three pictures from one of two notebooks, assigned randomly, while the experimenter read each accompanying vignette. The child was then asked to generate a thought that made her or him feel as the boys and girls did in the pictures. After the child had generated the thought, the experimenter encouraged him or her to elaborate on it and to think about how happy (or sad or just $O K$ ) she or he would feel if she or he were doing the activity or experiencing the situation the child had described.

For the vicarious embellishment of the affect-induction procedure, six sets of pictures and accompanying four-sentence descriptions were used. Each set contained three pictures of individuals displaying one of the three affects (happy, neutral, sad). The color pictures of children and family members were taken from popular magazines, and four adults judged the pictures to represent the appropriate affect based on the presence or absence of appropriate facial features (e.g., a smiling child for a picture in the happy set). The particular affect was emphasized in the description that accompanied each of the three pictures. An example of the vignettes is the following: "Look at this little boy. He sure looks happy. His dad likes him a lot, and they're having a lot of fun playing in the water together. He sure feels happy, doesn't he?" Because some children were exposed to the same affect at encoding and retrieval (e.g., Happy-Happy), two complete sets of the photos for each affect were used. Each of the sheets was covered with plastic, and the sheets were placed in notebooks that permitted the pages to be turned readily and helped direct the child's attention to the particular scene and story.

\section{Memory Task}

The stimuli in the memory task were $2413-\mathrm{cm} \times 10-\mathrm{cm}$ color photographs of 12 items from each of two semantic categories (vehicles and dishes), mounted on cardboard. Six pictures from each category were presented in the incidental learning phase, and the other items were used as distractors in the recognition test. The choice of categories and items was guided by pilot research. 
Children were seated at a small round table. On the table in front of the child was a clearly demarcated $28-\mathrm{cm} \times 22-\mathrm{cm}$ rectangle within which each stimulus was placed. The experimenter sat in a chair directly to the right of the child. A cassette recorder was also used, permitting the complete video and audio recording of each session.

Three red circles, each $7 \mathrm{~cm}$ in diameter, formed the outlines of happy, sad, and neutral (just $O K$ ) faces drawn on $15-\mathrm{cm} \times 10-\mathrm{cm}$ white cards. These cards were always presented in a standard order - happy, neutral, sad, from left to right -directly in front of each child and were used for the children's self-reports of their affective state and their ratings of the memory stimuli.

\section{Procedure}

Each child was accompanied to the experimental room by a female experimenter and seated at a table. Across from the child, in the direction he or she faced, was a video camera. Following brief conversation, the video camera silently recorded a 20 -second baseline segment of the child's facial expression while the experimenter was purportedly "looking over her list." No child seemed to be affected by the camera's presence. The experimenter then placed the three cards containing the faces in front of the child and proceeded to train the child in their use. Children readily identified the happy and sad faces, though some had to be told that the face in the middle meant feeling "just OK - not happy, not sad, but just OK." When the child could readily identify the affects portrayed by the three faces, she or he was asked to point to the face showing the one he or she felt most like. This constituted the initial self-report of affective state.

The initial affect induction appropriate to the child's assigned condition was then introduced. The child was then directed to look at the camera and to think about the thought while the experimenter did some writing. This part of the procedure took approximately 30 seconds. The experimenter then placed the three faces in front of the child, asking her or him to point to the one she or he felt most like.

Following the affect induction procedure, the experimenter told the child that she was trying to decide what toys to buy for a new playroom downstairs and that she would like the child to help her pick out some toys from a group of pictures of toys she had with her. Each of the 12 stimuli was presented sequentially for about 10 seconds, using a different random order for each child. Following the presentation of each item, the child was shown the three "faces" used earlier in order to assess the child's liking for each memory stimulus. This was accomplished by having each child point to the happy face if she or he liked the toy "a whole lot," the neutral face if "just a little bit," and the sad face if "not at all." 
After each of the 12 toys had been rated, the experimenter escorted the child to a playroom where the parent and the other experimenter were waiting. The child was seated at a small table and encouraged to play with the various toys.

Following the 10-minute play period, the male experimenter spent about 5 minutes playing with the child to establish rapport. The female experimenter then accompanied the child back to the experimental room. Again, a video recording of the child's facial affect was obtained and the experimenter asked the child to choose which of the three faces she or he felt most like. This was followed by a second affect induction, conducted in the same manner as the first. The child was asked to indicate again which of the faces depicted her or his affective state. The male experimenter then entered the room, blind to both affect inductions for the child, and told the female experimenter that she had a phone call. After the female experimenter left, the male experimenter sat down and proceeded to ask the child what she or he and the other experimenter had been doing, allowing the child to report anything about the first part of the session. The experimenter next said that the other experimenter forgot to write down what pictures of toys they had looked at, explaining that he would have to go and get them so he could record the ones they had seen. The child was then asked to name all the toys she or he could remember (free recall), and this was followed by asking the child if she or he could remember any additional vehicles or dishes (cued recall). When the child completed this cued recall phase, the experimenter thanked her or him for helping him and left the room, retrieving the 12 previously seen pictures plus the 12 distractor pictures. When the experimenter returned to the room, he asked the child to pick out the pictures she or he had seen before. The pictures were presented one at a time in a standard random order for each child using a yes/no recognition procedure.

Finally, the experimenter asked the child if the other experimenter had told her or him any stories and, if so, what they were. The child was also asked to recall the thoughts she or he had provided during the induction procedures. The session was concluded by the second experimenter's administering a third affect induction. This induction was always a positive one, used to counteract any negative affect that may have persisted from the earlier inductions.

\section{Independent Measurement of Affect}

Ratings of facial expressions and self-reports provided an independent assessment of subjects ${ }^{7}$ affective states and provided validation for the effectiveness of the affect induction procedure. Consistent with previous work 
(e.g., Barden et al., 1981), the videotape segments of children's facial expressions at baseline and after each induction were edited to a standard 12 seconds in length and used for facial ratings. The ratings were carried out by dividing each segment into three 4-second parts and rating each separately for happiness and sadness.

The facial features used to judge the presence or absence of the affects were taken from the work of Ekman, Friesen, and Ellsworth (1971), and the coding scheme was consistent with that used by Masters et al. (1979) and Barden et al. (1981). All ratings were made using 9-point scales, where 1 indicated the absence of a particular affect but did not imply the presence of another affect (e.g., "1-sadness" did not imply any degree of happiness). Several additional rules were also followed: (a) Each 4-second segment was viewed at least twice; (b) minor, fleeting expressions that suggested happy or sad affect were not coded; (c) mild happiness or sadness had to be present for 2 of the 4 seconds to be coded as present, and intense happiness or sadness had to be present for at least 1 second to be coded as present; (d) the child's face had to be visible for 2 of the 4 seconds for the segment to be coded (occasionally, a child turned away from the camera during a segment, making the segment unscorable), and (e) if a child's face was not fully visible (e.g., hands partially blocked face) but all the behavioral characteristics were consistent with a certain rating, the child was coded as exhibiting the particular affect.

All of the videotape segments were coded according to the above criteria by a rater who was unaware of the hypotheses for the study or the children's assigned conditions. A second rater (S.W.D.) was not naive to the hypotheses but was blind to the children's assigned conditions. The videotape segments for approximately $15 \%$ (10) of the subjects formed the basis for the reliability check. For each subject there were 124 -second segments, 6 from the baseline recordings and 3 each for encoding and retrieval. The judges had to agree on type, duration, and intensity of affect for an "agreement" to be scored. The mean reliability was .83 (range: $.75-.88$ ), obtained by dividing the number of agreements by the number of agreements plus disagreements.

For children's self-reports of affect, a choice of the "happy" face was assigned a 1.0 score, a choice of the "just OK" face was assigned a 2.0 score, and a choice of the "sad" face a 3.0 score for this measure. Children showed essentially no differentiation in their self-judgments of affect and most reported feeling mildly happy. At encoding the self-reports averaged 1.3,1.6, and 1.5 for children in the happy, neutral, and sad conditions, respectively. At retrieval the self-reports averaged $1.3,1.5$, and 1.8 for the happy, neutral, and sad conditions, respectively. Since children showed no variance on this measure, it will not be discussed further. 


\section{RESULTS}

\section{Measures of Affective State}

To assess the validity of the affect induction procedure, separate analyses of variance were performed on the ratings of facial affect at encoding and retrieval as well as on the children's self-reported affect. Facial ratings were unobtainable for four children at encoding and three children at retrieval due to poor tape quality.

Expressed Affect at Encoding. Mean happiness and sadness ratings at encoding and retrieval, in each affect induction condition, are shown in Table I. For the happiness ratings, a 2 (sex) $\times 3$ (affect condition at encoding) $\times 3$ (affect condition at retrieval) analysis of variance revealed a significant main effect of affect condition at encoding $(F(2,50)=11.2, p<.01)$. A planned comparison revealed that the facial ratings of happy affect were significantly higher for the children in the happy condition (3.32) than for the children in the sad condition $(1.17)(t(44)=3.87, p<.01)$. Children in the happy condition at encoding were also rated as showing significantly more happiness than children in the neutral condition $(1.32)(t(42)=3.40$, $p<.01)$.

A similar analysis of variance was conducted on the facial ratings of sad affect and revealed a marginally significant effect for affect condition at encoding $(F(2,50)=2.80, p=.07)$. A planned comparison revealed that facial ratings of sadness were significantly higher for the children in the sad condition (3.21) than for those in the happy condition (1.73) $(t(44)=-1.65$, $p=.05)$.

Expressed Affect at Retrieval. For the facial ratings of happiness, a $2(\mathrm{sex}) \times 3$ (affect condition at encoding) $\times 3$ (affect condition at retrieval)

Table I. Mean Facial Ratings of Happiness and Sadness at Encoding and Retrieval as a Function of Affect Condition

\begin{tabular}{lllll}
\hline & & \multicolumn{3}{c}{ Affect conditions } \\
\cline { 3 - 5 } & Affect dimension & Happy & Neutral & Sad \\
\hline \multirow{2}{*}{ Encoding } & Happiness & $3.32^{a}$ & $1.32^{a}$ & $1.17^{b}$ \\
& Sadness & $1.73^{a}$ & $2.50^{a}$ & $3.21^{b}$ \\
Retrieval & Happiness & $1.96^{c}$ & $1.29^{b}$ & $1.18^{a}$ \\
& Sadness & $1.48^{c}$ & $2.92^{b}$ & $2.45^{a}$ \\
\hline
\end{tabular}

${ }^{a} n=22$.

$b_{n}=24$

${ }^{c} n=23$. 
analysis of variance revealed a marginally significant main effect of affect condition at retrieval $(F(2,51)=2.88, p=.065)$. A planned comparison revealed that the facial ratings of happy affect were significantly higher for children in the happy affect condition (1.96) than for children in the sad affect condition $(1.18)(t(43)=1.93, p<.05)$.

A similar analysis of variance was performed on the facial ratings of sad affect at retrieval. While this analysis revealed no significant main effects or interactions, facial ratings of sad affect were higher for children in the sad affect conditions (2.45) than in the happy affect conditions (1.48), but this difference failed to reach significance $(t(43)=-1.43, p>.05)$. Children in the neutral affect condition at retrieval did show greater sadness (2.92) than children in the happy affect conditions (1.48) $(t=-1.95, p<$ $.05)$. Since affect inductions prior to retrieval were the second in a series, and research on multiple affect inductions suggest a strong primary effect, the apparently weaker impact of affect inductions at retrieval was not unexpected and was deemed consistent with the likelihood under natural conditions that mood states at retrieval will commonly be weaker than those at encoding (Barden et al., 1981; Barden et al., 1985).

\section{Memory Performance}

The mean numbers of correct items produced by children in the free recall, cued recall, and recognition tasks are contained in Table II. Across all conditions, free recall averaged 3.9 items, cuing, elicited an average of 1.1 additional items $(M=5.0)$, and in the recognition task memory was near ceiling for all children, averaging 11.8 items. Separate 2 (sex) $\times 3$ (affect at encoding) $\times 3$ (affect at retrieval) analyses of variance were performed for free recall, cued recall, and recognition memory. There were no significant main effects or interactions for any of the measures of memory.

During encoding, each child was asked to rate the 12 stimuli for likability. An average of 6.5 items were rated as "liked a lot," 2.6 as "liked a little bit," and 2.9 as "not liked at all." Three separate 2 (sex) $\times 3$ (affect at encoding) $\times 3$ (affect at retrieval) analyses of variance were performed on the children's likability ratings of the stimuli. Again, all main effects and interactions were nonsignificant, indicating no differential rating for items as a function of the child's emotional state at the time of the rating. In addition, three separate 2 (sex) $\times 3$ (affect at encoding) $\times 3$ (affect at retrieval) analyses of variance were performed for the recall of items rated "liked a lot," "liked a little," and "not liked." For these analyses also, all main effects and interactions were nonsignificant, except for an uninterpretable two-way interaction between encoding and retrieval conditions only for items rated positively ("liked a lot") $(F(4,54)=3.06, p<.05)$. Thus, it may be con- 
Table II. Mean Number of Items Correct in Free Recall, Cued Recall, and Recognition

\begin{tabular}{llcccc}
\hline & & \multicolumn{4}{c}{ Retrieval condition } \\
\cline { 3 - 6 } & Encoding condition & Happy & Neutral & Sad & $(M)$ \\
\hline Free recall $^{a}$ & Happy & 3.5 & 4.9 & 3.9 & $(4.1)$ \\
& Neutral & 3.9 & 4.1 & 3.3 & $(3.8)$ \\
& Sad & 4.0 & 3.9 & 3.4 & $(3.8)$ \\
& $(M)$ & $(3.8)$ & $(4.3)$ & $(3.5)$ & $(3.9)$ \\
Cued recall $^{b}$ & Happy & 4.5 & 5.9 & 4.8 & $(5.1)$ \\
& Neutral & 4.5 & 5.6 & 4.6 & $(4.9)$ \\
& Sad & 4.5 & 5.3 & 4.9 & $(4.9)$ \\
& $(M)$ & $(4.5)$ & $(5.6)$ & $(4.8)$ & $(5.0)$ \\
Recognition $^{c}$ & Happy & 11.9 & 12.0 & 11.8 & $(11.9)$ \\
& Neutral & 11.8 & 11.9 & 11.6 & $(11.8)$ \\
& Sad & 11.9 & 12.0 & 11.8 & $(11.9)$ \\
& $(M)$ & $(11.8)$ & $(12.0)$ & $(11.7)$ & $(11.8)$ \\
\hline
\end{tabular}

a Mean for same presentation $\times$ test condition $=3.7$.

Mean for different presentation $\times$ test condition $=4.0$.

${ }^{b}$ Mean for same presentation $\times$ test condition $=4.0$.

Mean for different presentation $\times$ test condition $=4.9$.

'Mean for same presentation $\times$ test condition $=11.9$.

Mean for different presentation $\times$ test condition $=11.9$.

cluded that there was no evidence that the type of items retrieved from memory (e.g., memory content) was affected by the affective state of the child at encoding or retrieval.

\section{DISCUSSION}

\section{State-Dependent Learning in Young Children}

The independent assessments of children's spontaneous facial expressions of affect indicated that children in the happy and sad conditions were experiencing appropriate affects. Analysis of the memory data, however, demonstrated no state-dependent effects of affective state on free recall, cued recall, or recognition of memory. Nor did children show enhanced memory performance when the encoding and retrieval affective states were congruent (e.g., Happy-Happy).

The absence of effects on cued recall and recognition memory in the present study was expected and consistent with previous research, but the absence of any effect on free recall was contrary to predictions and some previous findings (e.g., Bartlett \& Santrock, 1979; Bartlett, Burleson, \& Santrock, 1983) but not others (Nasby \& Yando, 1982). The studies by Bartlett and his colleagues differ methodologically from the present one in a number 
of ways, and the possible importance of some of these differences will be considered in a succeeding section. Consistent with the present findings, Nasby and Yando (1982, Experiment 1) found no evidence for state-dependent learning with a sample of normal fifth-graders, using affect induction and memory test procedures similar to those employed in the present study. Thus, evidence for state-dependent learning in children is inconsistent at this point. On the other hand, research with normal adults, employing nonhypnotic affect inductions, is consistent with the present results and those of Nasby and Yando (1982) in failing to demonstrate state-dependent learning with affect inductions (e.g., Isen, Shalker, Clark, \& Karp, 1978), although research with adult depressive patients has reported quite robust effects (e.g., Weingartner, Murphy, \& Stillman, 1978). This suggests that normal variation in mood states does not have much impact on memory in children or adults.

\section{Methodological Issues in Research on Affect and Memory}

The differences in the methodologies employed by various researchers in their attempts to explore the role of affect in memory processes are many. They include subject variables, such as the ages of the subjects studied (preschool children, school-age children, and adults) or special characteristics of certain groups of subjects (e.g., Bower's, 1981, work with adult hypnotics). Other possibly important factors that vary from study to study include the length of the retention interval, the type of memory required by the experiment, the nature of the material to be remembered, and the method and number of affect inductions. For example, the retention intervals employed have ranged from practically zero (Nasby \& Yando, 1982) to a couple of minutes (Bartlett \& Santrock, 1979), 10 minutes (Bartlett et al., 1983), and 15 minutes in the present study.

One factor that may be particularly important in determining whether affect appears to influence memory is the type of memory process invoked during the encoding of information. Bartlett and Santrock (1979), Nasby and Yando (1982), and Bartlett et al. (1983) all used intentional learning paradigms in contrast to the incidental one used here. In incidental memory there is little to emphasize the distinctiveness of the material, and this may have contributed to the absence of state-dependent effects on free recall memory in the present study. Note, however, that the choice of an incidental memory task was made on the hypothesis that such a task would be likely to maximize the subjects' use of affect as a memory cue, rather than such memory strategies as rehearsal or categorical recall, often used by older subjects in deliberate memory tasks (Brown \& DeLoache, 1978; Flavell \& Wellman, 1977). The present results bring this hypothesis into question. It 
may be that affect is most likely to influence memory processes (especialiy in young children) only when the material to be remembered has a certain distinctiveness, gained either through the use of intentional memory processes by the subject (such as rehearsal), through the emotional intensity of the content to be remembered, or through the intensity of the affective states of the individual at learning and recall. Contrary to the initial hypothesis, it may be that only under circumstances such as these will any state-dependent or "cognitive loop" processes become operative. This interpretation implies, further, that any apparent developmental changes in the role of emotion in memory may actually be mediated by nonaffective factors, such as the development of metamemory strategies.

Another aspect of memory processing that may influence the effects of emotion on storage and retrieval is whether the material is verbal in nature versus iconic (e.g., visual or aural). Isen (1984) has suggested that factors such as emotion may be most likely to exert an influence on memory processes when the material to be recalled is not readily integrated into associated networks or otherwise encoded and retrieved with relative ease. The visual stimuli employed in the present study were pictures of toys, items which are likely to be particularly salient and meaningful to young children and which thus may be learned and remembered in a fashion that is resistant to intrusive effects of either the child's own emotional state or affect related to individual items (in the present study, children's liking for a given toy). Future research might well vary the types of stimuli along dimensions such as meaningfulness or associative richness to evaluate the hypothesis that the effects of emotion on memory are systematically influenced by the type of material to be learned and remembered. Again, the suggestion is that normal variations in mood may not have broad or pervasive effects on memory.

A final methodological factor that must be considered is that of the method of affect induction. Some of the research with adults in this area (e.g., Bower, Monteiro, \& Gilligan, 1978) has utilized hypnotism to achieve certain affective states, in the process raising issues of generalizability and experimenter demand characteristics. Examination of various affect induction procedures employed with children reveals differences that may be equally problematic. Some researchers ask children to generate thoughts of a particular affective valence and then to ruminate on them (e.g., Barden et al., 1981; Bartlett et al., 1983), some use story content and experimenter modeling to induce affect (e.g., Bartlett \& Santrock, 1979), and others rely on a combination of condition-appropriate picture/story cues and the child's own remembrances, as in the present investigation.

Though Teasdale and Taylor (1981) found no differences in accessibility of memories of female college students, using two different induction techniques, it would be inappropriate to use this lack of evidence to conclude 
that different induction techniques with children should not have differential effects on memory, especially in light of demonstrated effects from arousal as well as valence (Masters et al., 1979) on children's learning, or of different foci of attention (self vs. other) within the affect induction procedure (Barnett, King, \& Howard, 1979) on children's altruism. During development, children only gradually acquire many of the cognitive competencies that characterize adults (Brown \& DeLoache, 1978; Siegler, 1978), and differences in the cognitive aspects of different affect inductions with children may have interactive effects with developing memory processes in ways that are different from those on "mature" (adult) memory processes.

Unfortunately, the great variability across affect inductions in memory research with children makes it impossible at this time to discern any clear relation between the character of an affect induction and the presence or absence of any effects on memory. In addition, the study of the relationship between affect and memory makes essential the use of independent assessments of affective state with the use of facial ratings. The absence of these ratings in some studies (e.g., Bartlett \& Santrock, 1979) makes careful crossstudy comparisons impossible. It would be well for future research with children to employ more than a single type of induction in any given study and to take special care to denote the character of the affect induction when considering the implications of any findings or how they relate to results from prior research.

\section{REFERENCES}

Barden, R. C., Garber, J., Duncan, S. W., \& Masters, J. C. (1981). Cumulative effects of induced affective states in children: Accentuation, inoculation, and remediation. Journal of Personality and Social Psychology, 40, 750-760.

Barden, R. C., Garber, J., Leiman, B., Ford, M. E., \& Masters, J. C. (1985). Factors governing the effective remediation of negative affect and its cognitive and behavioral consequences. Journal of Personality and Social Psychology, 49, 1040-1053.

Barnett, M. A., King, L. M., \& Howard, J. A. (1979). Inducing affect about self or other: Effects on generosity in children. Developmental Psychology, 15, 164-167.

Bartlett, J., Burleson, G., \& Santrock, J. W. (1983). Emotional mood and memory in young children. Journal of Experimental Child Psychology, 34, 59-76.

Bartlett, J. C., \& Santrock, J. W. (1979). Affect-dependent episodic memory in young children. Child Development, 50, 513-518.

Bower, G. H. (1981). Mood and memory. American Psychologist, 36, 129-148.

Bower, G. H., Monteiro, K. P., \& Gilligan, S. G. (1978). Emotional mood as a context for learning and recall. Journal of Verbal Learning and Verbal Behavior, 17, 573-585.

Brown, A. L., Bransford, J. D., Ferrara, R. A., \& Campione, J. C. (1983). Learning, remembering, and understanding. In P. H. Mussen (Gen. Ed., J. H. Flavell \& E. M. Markman, Vol. Eds.), Handbook of child psychology: Vol. III: Cognitive development (pp. 77-166). New York: Wiley.

Brown, A. L., \& Deloache, J. S. (1978). Skills, plans, and self-regulation. In R. S. Siegler (Ed.). Children's thinking: What develops? (pp. 3-35). Hillsdale, New Jersey: Erlbaum. 
Colpaert, F. C., \& Rosecrans, J. A. (Eds.). (1978). Stimulus properties of drugs: Ten years of progress. Amsterdam: Elsevier/North-Holland Biomedical Press.

Ekman, P., Friesen, W. V., \& Ellsworth, P. (1971). Emotion in the human face: Guidelines for research and integration of findings. New York: Pergamon Press.

Flavell, J. H., \& Wellman, H. M. (1977). Metamemory, In R. V. Kail, Jr. \& J. W. Hagen (Eds.), Perspectives on the development of memory and cognition (pp. 3-33). Hillsdale, New Jersey: Erlbaum.

Harris, M. B., \& Siebel, C. E. (1975). Affect, aggression, and altruism, Developmental Psychology, $11,623-627$.

Isen, A. M. (in press). Affect, cognition, and social behavior. In R. Wyer \& T. Srull (Eds.), Handbook of social cognition.

Isen, A. M. (1984). Affect, cognition, and social behavior. In R. Wyer \& T. Srull (Eds.), Handbook of social cognition. Hillsdale, New Jersey: Erlbaum. $o g y, 36,1-12$.

Istomina, Z. M. (1975). The development of voluntary memory in preschool-age children. Soviet Psychology, 13, 5-64. (Original work published 1948)

Markman, E. M. (1981). Two different principles of conceptual organization. Advances in Developmental Psychology, 1, 199-236.

Masters, J. C., Barden, R. C., \& Ford, M. E. (1979). Affective states, expressive behavior, and learning in children. Joumal of Personality and Social Psychology, 37, 380-390.

Moore, B. S., Underwood, B., \& Rosenhan, D. L. (1973). Affect and altruism. Developmental Psychology, 8, 99-104.

Nasby, W., \& Yando, R. (1982). Selective encoding and retrieval of affectively valent information: Two cognitive consequences of children's mood states. Journal of Personality and Social Psychology, 43, 1244-1253.

Ornstein, P. A. (1978). Memory development in children. Hillsdale, New Jersey: Eribaum.

Perlmutter, M., \& Myers, N. A. (1979). Development of recall in 2- to 4-year-olds. Developmental Psychology, 15, 78-83.

Reichenbach, L. C. (1984). Parental divorce: Affective experience and affective response. Unpublished doctoral dissertation, Vanderbilt University.

Rosenhan, D. L., Underwood, B., \& Moore, B. S. (1974). Affect moderates self-gratification and altruism. Journal of Personality and Social Psychology, 30, 546-552.

Siegler, R. S. (1978). Children's thinking: What develops? Hillsdale, New Jersey: Erlbaum.

Teasdale, J. D., \& Taylor, R. (1981). Induced mood and accessibility of memories: An effect of mood state or of induction procedure? British Journal of Clinical Psychology, 20, 39-48.

Todd, C. M., \& Perlmutter, M. (1980). Reality recalled by preschool children. In M. Perlmutter (Ed.), New directions for child development: Children's memory (No. 10). San Francisco: Jossey Bass.

Underwood, B., Moore, B. S., \& Rosenhan, D. L. (1973). Affect and self-gratification. Developmental Psychology, 8, 209-214.

Weingartner, H. (1984). Psychobiological determinants of memory failures. In L. R. Squire \& N. Butters (Eds.), Neuropsychology of memory (pp. 203-212). New York: Guilford Press.

Weingartner, H., Murphy, D. L., \& Stillman, R. C. (1978). Mood state dependent learning. In F. C. Colpaert \& J. A. Rosecrans (Eds.), Stimulus properties of drugs: Ten years of progress (pp. 445-453). Amsterdam: Elsevier/North-Holland Biomedical Press. 